\title{
Arte e sociedade
}

\author{
Allan de Paula
}

Há pouco mais de 180 anos o ritual se repete. As pessoas, ansiosas, preparam-se durante o dia, vestem-se à caráter, evitam chegar ao teatro - locus habitual do rito - fora do horário, sentam-se e aguardam o início do programa. Enquanto aguardam, observam-se mutuamente - outra espécie de ritual: olhares de despeito, curiosidade, olhares enamorados ou de escárnio. De repente, as luzes são apagadas (celulares são, ou deveriam ser..., desligados) e, momento sublime, um sujeito de fraque entra no palco, cumprimenta os músicos, ergue uma pequena vareta, olha novamente para os musicistas e, então, dá início ao concerto da noite. No programa, músicas que há mais de um século freqüentam as salas de concerto do mundo inteiro, como concertos de Bach, sinfonias de Mozart, sonatas de Beethoven ou óperas de Wagner. Às vezes, se a orquestra é competente, e pode dar-se a luxos, aparecem "coisas" como Stravinski ou Béla Bartók - mesmo assim, com muita cautela, pois o público gosta mesmo é dos "clássicos".

Para alguns, ouvir uma boa orquestra sinfônica executando uma obra consagrada é uma das grandes experiências que a modernidade oferece ${ }^{2}$. Para muitos amantes da música, a orquestra representa o aperfeiçoamento supremo a que a arte musical pôde chegar - opinião conservadora, à medida que nega futuras evoluções ou mudanças em uma fórmula que corresponde a um momento específico da música ocidental. A orquestra sinfônica, como formação musical, e da maneira como a conhecemos atualmente - um regente e cerca de 60 músicos -, é uma criação típica do século XIX, ou ainda, é uma "invenção" do Romantismo e das características que a música, no Ocidente, assumiu naquele período ${ }^{3}$. Bach, por exemplo, tinha que se contentar com, no máximo, 20 músicos. Isto não quer dizer que a orquestra não possua uma história, pelo contrário: pode-se retraçar sua genealogia a partir de formações musicais que surgem no Ocidente desde o século XVI e que, com diferenças regionais, se desenvolvem na Europa. Nesse sentido, e a grosso modo, a orquestra sinfônica é uma formação tipicamente alemã, desenvolvida no seu centro musical, Viena. Aliás, a capital do Império Austro-Húngaro ficará para a

\footnotetext{
'Graduação-História/UFPR.

${ }^{2}$ SPENCE, K. O livro da música. São Paulo : Círculo do Livro, 1979. p. 18.

${ }^{3}$ TRAVASSOS, E. Mandarins milagrosos : arte e etnografia em Mário de Andrade e Béla Bartók. Rio de Janeiro: Funarte, 1997. p. 29-84.
} 
música sinfônica alemã da mesma forma que Paris para a ópera e o bel canto italianos ${ }^{4}$.

Embora tenha surgido em um momento específico da história da música, a orquestra sinfônica é, no entanto, resultado de processos muito mais amplos: as mudanças na estrutura de comportamento dos indivíduos e as transformações da estrutura das formações sociais. Este fato parece-me totalmente ignorado, ou melhor, pouco considerado pelas obras de história e análise musical que, com uma visão um tanto quanto romântica, apresentam o desenvolvimento da música no Ocidente como uma mera sucessão de estilos dependentes e criados pelo "gênio" de alguns compositores 5 . Dessa forma, a ópera seria uma "invenção" de Monteverdi, enquanto que a fuga seria obra do gênio de Bach. O que nos escapa neste tipo de abordagem é o caráter social e coletivo da música e das formas musicais. Bach não inventou a fuga, embora a tenha desenvolvido de maneira sublime; o mesmo com a ópera em relação à Monteverdi. Tomei o exemplo da orquestra para iniciar o texto, mas poderia citar outros casos, como a própria ópera, a música de câmara, ou ainda, formas musicais mais específicas como a suíte, o concerto, a sinfonia ou o canto gregoriano. Tais formas musicais, menos que frutos da sublimação de alguns poucos indivíduos, são resultados da interação e da interdependência de muitos deles. Da mesma forma que mudanças na estrutura dos comportamentos individuais levaram a um refinamento dos costumes, elas incorreram também em transformações no gosto musical e na sensibilidade artística em geral. Foram estas transformações na sensibilidade, mais do que "achados" de alguns "gênios", que levaram ao desenvolvimento das formas musicais no Ocidente. E mais: a transformação desta sensibilidade, como parte de mudanças na estrutura do comportamento individual, está diretamente ligada à mudanças nas redes de interdependência que ligam os indivíduos entre si, ou seja, às transformações das estruturas sociais.

É impossível, quando se fala em mudanças na estrutura de comportamento relacionadas a transformações de estruturas sociais, não remeter à Norbert Elias. A correlação entre essas mudanças é a base daquilo que ele denominou processo civilizador - processo que, segundo Elias, "...constitui uma mudança na conduta e sentimentos humanos rumo a uma direção muito específica" . Direção: um autocontrole das pulsões e desejos

\footnotetext{
${ }^{4}$ SPENCE, op. cit., p. 64.

${ }^{5}$ Sobre história da música, Cf. ANDRADE, M. Pequena história da música. Belo Horizonte : Editora Itatiaia, 1987; CARPEAUX, O. M. Uma nova história da música. Rio de Janeiro : Zahar Editores, 1958; COSTA, C. L da. Uma breve história da música ocidental. São Paulo : Ars Poética, 1992. Embora mais antiga, a obra de Mário de Andrade é , a meu ver, a que melhor leva em conta o aspecto social da música.

${ }^{6}$ ELIAS, N. O processo civilizador. Rio de Janeiro : Jorge Zahar Editor, 1993. v. 2 : formação do estado e civilização, p. 193-194.
} 
individuais até um ponto em que se possa falar que este autocontrole constitui uma "segunda natureza" do homem ${ }^{7}$. Todo esse processo, para o pensador alemão, está diretamente ligado ao crescimento, no Ocidente, do grau de diferenciação social e seu conseqüente aumento da divisão das funções sociais e à complexificação das redes de interdependência, às quais os indivíduos estão integrados. A posição e a estabilidade do indivíduo dentro da sociedade passa, então, a depender da emolduração na manifestação dos seus desejos.

Ora, se os desejos e pulsões individuais passam por um processo de controle, o mesmo se dá com a sensibilidade dos indivíduos. Espaço privilegiado para a manifestação desta sensibilidade, a arte acompanha suas mudanças; temos, então, a sucessão de estilos e padrões artísticos. Ou seja, pode-se afirmar que as transformações e mudanças ocorridas na arte ocidental, desde o período medieval, estão ligadas a mudanças na sensibilidade e na manifestação dos desejos, que, por sua vez, se ligam às mudanças das estruturas sociais. A música, como manifestação artística, não está isenta e imune a esta cadeia de relações, mas, conforme afirmei anteriormente, os historiadores preocupados com suas transformações não levam tal dado em consideração como deveriam. Elias nos deu uma pista desta relação música-processo civilizador quando escreveu sua obra "Mozart: sociologia de um gênio", na qual enfatiza as coerções sociais que levaram Mozart, enquanto artista, a dar fim à vida de Mozart, enquanto homem. Entretanto, voltarei mais adiante a este ponto, o das coerções sociais e sua relação com a arte. Chamo atenção, em um primeiro momento, para a possibilidade de compreendermos melhor, seguindo os passos de Elias, a gênese e a sucessão de estilos e formas da música ocidental, observando-os em relação às formações sociais pelas quais foram produzidos.

Didaticamente, costuma-se dividir a evolução da música no Ocidente em alguns períodos que se sucedem cronologicamente: música medieval, música renascentista, barroco, classicismo, romantismo e música contemporânea (ou melhor, música do século XX...). Esses períodos, utilizados pelos historiadores da música, não coincidem cronologicamente com os períodos homônimos utilizados para outras manifestações artísticas, como, por exemplo, a literatura ${ }^{8}$. Goethe, considerado um marco no romantismo literário, era bem mais velho que seu "correspondente" na música, Beethoven. Em relação à música, no entanto, essas divisões cronológicas realmente abarcam momentos estilísticos distintos da música ocidental, sendo possível falar em um

\footnotetext{
${ }^{7}$ Id., p. 197.

${ }^{8} \mathrm{O}$ interessante é que os livros de história da arte excluem, geralmente, a música e a literatura, haja vista seu desenvolvimento autônomo. Há, portanto, livros sobre história da arte, história da literatura e história da música.
}

82

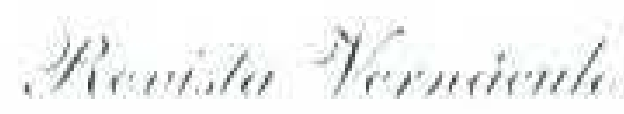


"estilo barroco" de compor, ou ainda, uma forma musical que possa ser definida como medieval.

Uma crítica que se pode fazer a estas periodizações historiográficas é que elas só consideram, como toda a história, as manifestações musicais escritas. Em determinados casos, os estilos musicais reconstruídos pelos historiadores só revelam a música praticada nos centros de poder. O prejuízo para o nosso conhecimento é tanto maior quanto for o do recuo temporal. Daí porque a música medieval geralmente é confundida com o canto gregoriano, haja vista a posição de destaque da Igreja no período. Assim, a música praticada por camponeses, ou melhor, fora do adro ou da corte, até a metade do século XX, era totalmente desconhecida, já que não tinha sido registrada. Este quadro só começou a ser revertido quando historiadores e etnomusicólogos começaram, conjuntamente, a pesquisar músicas de tradição oral. Mesmo assim, para períodos muito recuados no tempo, como Idade Média e Renascença, questões como afinação ou ainda o próprio timbre dos instrumentos são motivos de grandes controvérsias. Não cabe aqui, no entanto, aprofundarmo-nos por esta vereda. Para o objetivo deste trabalho, as periodizações citadas, mesmo com suas imprecisões, serão úteis - embora o leitor deva ter em mente que estamos lidando com aquilo que, modernamente, convencionou-se chamar de música erudita.

Comecemos pela música medieval. Este termo, a meu ver, denota a produção sonora realizada entre os século VI e XI, aproximadamente ${ }^{9}$. Essa música seria caracterizada por um estilo monódico (uma só linha melódica), cantada e sem uso de instrumentação. É partir daí que se desenvolve o canto gregoriano e o início de um sistema de notação musical ${ }^{10}$. Esse caráter simples, quase hipnótico, da música deste período, se deve ao fato do centro irradiador desse tipo de música se localizar na Igreja. Até o século $\mathrm{X}$, os ditames e prescrições relativos às artes estão nas mãos dos prelados da Igreja de Roma. A música medieval, cujo registro ficou para a posteridade, é uma música sacra, de religiosidade expressiva, que reflete um ambiente trágico, milenarista - a proximidade do ano 1000. Aliás, nesse momento não há ainda uma separação das artes: todas são correlatas e têm um só objetivo: louvar a Deus. Isto equivale dizer que não se pode separar este tipo de música de suas funções litúrgicas.

O período seguinte, que abrange a música renascentista, vai do século XII ao século XVI. Em relação ao período anterior já se observam mudanças

\footnotetext{
${ }^{9}$ Essas balizas cronológicas devem ser tomadas com cautela. Clarissa da Costa prefere situar a música medieval entre os séculos IV e XIV, subdividindo-a em dois períodos: a fase românica e a fase gótica. A meu ver, o que ela chama de fase gótica, já faria parte do Renascimento, pois é marcante o uso de polifonias - o uso de diversas vozes simultâneas e independentes. Cf. COSTA, op. cit., p. 15-38.
}

${ }^{10}$ Id., p. 15-24; ANDRADE, op. cit., p. 33-47.

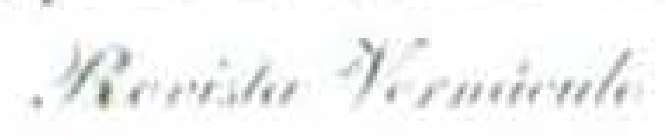


estilísticas importantes: o uso de instrumentação - embora com uma função meramente de acompanhamento - e, sobretudo, o desenvolvimento da polifonia. As formas musicais se diversificam com o surgimento de madrigais e motetos e isso se deve ao fato de que a Igreja perde sua supremacia enquanto centro da vida social. Um novo tipo de formação social começa a se desenvolver entre os séculos X e XIV, e passa a disputar poder e espaço com o hábito de São Pedro: as cortes aristocráticas ${ }^{11}$. Embora somente muito mais tarde - com a posterior unificação das cortes, a formação dos Estados e a primazia de uma corte régia - apareça aquilo a que Elias denotou "sociedade de corte" (cuja expressão máxima foi o Palácio de Versalhes sob o reinado de Luís XIV), é durante esse período, séculos X a XIV, que tais cortes se organizam. A historiografia cunhou o termo, "feudalismo", já clássico, para designar esse período de organização das cortes e de poder descentralizado, e o próprio Elias nos apresenta sua sociogênese $\mathrm{e}^{12}$. Com o desenvolvimento das cortes, novas formas musicais, diferentes da música sacra, vão surgindo, ou seja, desenvolvese uma música profana. Além disso, nas cortes, a música é separada das outras manifestações, ao contrário do que acontecia na música sacra. Mesmo esta forma de música sofre mudanças: com o desenvolvimento da arte gótica, a música sacra, monódica, começa a sofrer alguns "enfeites", como o acompanhamento de órgão ou até mesmo o acréscimo de alguma vozes, descaracterizando a monodia, ao cantochão. No entanto, estas mudanças são graduais e não alteram a funcionalidade da música na Igreja, e o seu uso pela liturgia.

O barroco, período posterior que compreende os séculos XVII e parte do XVIII, é marcado por uma espécie de "retrocesso". A polifonia renascentista, que se espalhara pelas cortes e já se desenvolvera bastante também na música sacra, chega a tal ponto de desenvolvimento que peças para 40 vozes - com várias letras diferentes cantadas ao mesmo tempo! - foram compostas. Diante desse quadro, uma reação foi articulada no seio de algumas cortes italianas no início do século XVII. Com ideais voltados para a Antigüidade clássica, um grupo conhecido como Camerata Fiorentina, liderada pelos condes Bardi e Corsi, passou a pregar um estilo musical recitativo, monódico, baseado na tragédia grega. A idéia era evitar os excessos da polifonia praticada na época que, segundo a Camerata, era bárbara e destruía a expressividade do texto ${ }^{13}$. Quando compositores, contratados por esses nobres, como Jacopo Peri e Claudio Monteverdi, transformaram este canto falado em um recitativo dramático, deu-se início o desenvolvimento da ópera.

\footnotetext{
${ }^{11}$ ELIAS, op. cit., p. 23-192.

${ }^{12}$ Id., p. $58-64$.

${ }^{13}$ HARNONCOURT, N. O diálogo musical : Monteverdi, Bach e Mozart. Rio de Janeiro : Jorge Zahar Editor, 1993. p. 26-28.
}

84

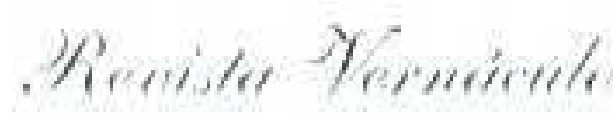


Monteverdi, por sua vez, conseguiu unir as propostas italianas à polifonia que vinha da Renascença empregando um recurso interessante: à voz cantada era adicionada outras vozes formadas por instrumentos. Este recurso, utilizado por vários compositores desta época, representa o início do desenvolvimento de uma linguagem puramente instrumental. A grosso modo, pode-se falar que os instrumentos começam a se libertar da voz, a quem deviam acompanhar. Nikolau Hanoncourt afirma que este é momento do surgimento de um discurso musical - um "repertório de figuras" que possibilitam a comunicação através da música, sem o auxílio de palavras ${ }^{14}$. É no barroco que a música instrumental, que já vinha se desenvolvendo desde o Renascimento, ganha seus primeiros "gênios".

No entanto, isto não se dá na Itália, que cria uma tradição de música cantada, e sim na Alemanha, ou melhor, no norte protestante da Europa.

A Reforma mudou o equilíbrio dos centros produtores de música. Como afirma Otto Maria Carpeaux, nos países que se mantiveram católicos, as cortes permaneceram muito mais secularizadas do que nos países protestantes, haja vista o próprio caráter mais interiorizado da fé luterana. Enquanto que nos países católicos a distinção entre música sacra e música profana continua operando, nos países protestantes a religiosidade passa a ser marcante inclusive em ambientes profanos. Nas cortes protestantes, mesmo em ocasiões festivas, a gravidade e a seriedade dos temas musicais é notável ${ }^{15}$. No entanto, uma mudança importante ocorre: a Igreja reformista, ao contrário da Igreja de Roma, estimula o desenvolvimento da polifonia. Desenvolve-se, então, uma polifonia vocal que se manifesta na forma de cantatas e motetos. Além disso, os mesmos compositores que estão compondo para o culto luterano compõem para a corte em um estilo puramente instrumental, desenvolvendo ainda mais a escrita polifônica. É o caso típico de Bach, que compõe música tanto para o culto quanto para a corte, mas sempre com um senso religioso muito forte.

$\mathrm{O}$ período barroco correspondeu ao apogeu da sociedade de corte. Elas, as cortes, ditavam as normas e os limites que os estilos musicais deveriam seguir; por isso mesmo, eram o local onde os compositores deveriam trabalhar. Com a música barroca, pode-se dizer que as bases do discurso musical no Ocidente, aquele "repertório de figuras", são finalmente estabelecidas, após uma gênese de aproximadamente dez séculos. Pensando na metáfora entre música e linguagem, é como se disséssemos que com a música barroca são introduzidas as últimas "palavras" do vocabulário musical. À posteridade, restaria montar novas "frases". Por isso mesmo é que, quando irrompe o

${ }^{14}$ Para Harnoncourt, este "repertório" teria sido desenvolvido por Monteverdi, Bach e Mozart. Cf. HARNONCOURT, $N$. O discurso dos sons : caminhos para uma nova compreensão musical. Rio de Janeiro: Jorge Zahar Editor, 1990. p. 165-174.

${ }^{15}$ CARPEAUX, op. cit., p. 28-29.

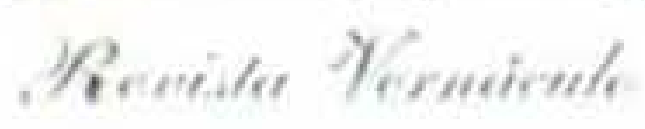


período da história da música conhecido como "classicismo", correspondente a segunda metade do século XVIII, as inovações musicais mudam de terreno - o que talvez explique a brevidade do período, que teve em Haydn, Gluck, mas, sobretudo, em Mozart, seus principais ícones. As inovações estilísticas do classicismo se limitaram ao aperfeiçoamento de algumas formas musicais derivadas do barroco, como o concerto e a sinfonia, que adquiriram formas sublimes nas mãos de Mozart. No entanto a maior inovação do período, a meu ver, não foi propriamente estilística - as "palavras" já estavam dadas - mas, digamos que, ontológica: o classicismo trouxe, pela primeira vez, a figura do compositor ansioso por reconhecimento. O músico que deseja ser reconhecido por sua arte e que receba, graças à sua música, um novo status social. É esta ansiedade que Elias retrata com maestria em Mozart. A grande inovação a que o classicismo se propõe está fora do campo musical: a mudança na posição social do artista e, no limite, uma nova compreensão da arte musical. Isto não ocorre, entretanto, como um fenômeno isolado. O século XVIII assiste a uma mudança de perspectiva no que podemos denominar de percepção humana da natureza, e a arte, enquanto representação, não estava imune a esta transformação. Nessa época, pela primeira vez na história, tem-se a percepção de que a música é uma forma de comunicação; esta questão estará na pauta dos principais pensadores da época. A questão de linguagem musical passou a ser discutida com tal recorrência que Lévi-Strauss chegou a ironizar, num ensaio recente sobre música, que "...em pleno século XVIII, os princípios sobre os quais Saussure fundará a linguística estrutural são claramente enunciados, mas a respeito da música..."16. Rousseau, em seu "Ensaio sobre a Origem das Línguas", escrito entre 1755 e 1760 , dedica alguns capítulos à análise da arte musical e de suas origens. O pensador deixa muito clara sua idéia de uma música como "imitação da natureza", que aja sobre nós "...como sinais de nossas afeições, de nossos sentimentos" "17. A preocupação com a idéia de conhecimento e representação da natureza e dos limites da arte musical, nesse sentido, era evidente. Numa daquelas coincidências que só servem para ilustrar textos, o ano de 1781, o mais importante da vida de Mozart - quando resolve se manter como compositor autônomo- é o ano de lançamento de uma obra que revolucionaria a filosofia justamente por propor uma nova perspectiva do ato de conhecer, a "Crítica da Razão Pura". Enquanto Kant propõe uma nova abordagem do conhecimento, Mozart, de certa maneira, reivindica uma nova maneira de ouvir, de se relacionar com a arte musical e com aquele que a inventa. Este desejo, da maneira como Mozart o perseguiu, era no entanto uma novidade. Nenhum dos filósofos iluministas que escreveram sobre música no

\footnotetext{
${ }^{16}$ Cf. LÉVI-STRAUSS, C. Olhar, escutar e ler. São Paulo : Companhia das Letras, 1997. p. 75.

${ }^{17}$ Cf. ROUSSEAU, J. J. Ensaio sobre a origem da línguas. São Paulo : Nova Cultural, 1999. p. $309 ; 315$.
} 
século XVIII, como Rousseau ou D'Alembert, reivindicavam um novo status social para o artista ${ }^{18}$. Podiam se preocupar com o valor e os limites da música, mas não questionavam a posição social do músico. Mozart desejava para si a liberdade e a autonomia de que pintores e literatos já desfrutavam há tempos. Mas aquilo que na pintura já vinha ocorrendo desde, pelo menos, o século XVI - quando o artista adquire uma autonomia em relação ao mecenas - na música teria de esperar os ventos quentes que soprariam da França, a partir de 1789, e quando começa a ocorrer - uma mudança na própria idéia da arte musical e sua função social - tem-se o advento do Romantismo. A partir desse período, muda toda a relação artista-público, pois a música não é feita apenas para uma corte e seu deleite. A obra musical, nesse sentido, ganha um novo status ontológico. É o que Elias chama de "arte de artista"19. No Romantismo aparecem termos como genialidade, talento e inspiração enquanto categorias de análise estética. Hegel, com o intuito de criticá-las, diria que

deixou-se de considerar a obra de arte como produto de uma atividade geral, formal, abstrata e mecânica, para declarar que ela é o produto de um espírito especialmente dotado e que o homem assim dotado só tem de se entregar à sua específica singularidade sem nenhuma preocupação, aliás nociva à sua atividade, com os fins aonde essa entrega o poderá levar. Resumiu-se esta maneira de ver declarando que a obra de arte é uma criação do gênio, do talento. ${ }^{20}$

Tem-se, portanto, uma nova percepção da arte e do artista, com uma maior valorização de ambos. Observando os momentos anteriores é possível pensarmos que, nesse momento específico, o músico ganha finalmente o status de artista; e, como tal, recebe um tratamento diferenciado. Beethoven foi alvo de uma verdadeira religião por parte de muitos de seus contemporâneos, que já tinham dele a idéia de gênio.

Em termos de evolução musical, paremos neste ponto: o do nascimento romântico do músico. A evolução "música medieval renascimento - barroco - música clássica" já serve para pensarmos o papel da arte dentro do processo civilizador proposto por Norbert Elias. Além disso, tais estilos musicais estão correlacionados com a corte, formação social tão bem descrita por Elias e que foi alvo de muitas de suas preocupações.

Elias vê dois momentos para a arte no Ocidente, que ele identifica como "arte de artesão" e "arte de artista". A diferenças entre as fases seriam dadas pela relação artista-consumidores, além de operarem em momentos

\footnotetext{
${ }^{18}$ d'Alembert publicou em 1752 um tratado sobre música intitulado "Elementos de música". Cf. LÉVI-STRAUSS, op. cit., p. 37

${ }^{19}$ ELIAS, N. Mozart : sociologia de um gênio. Rio de Janeiro : Jorge Zahar Editor, 1995. p. 45-52.

${ }^{20}$ Cf. HEGEL, G. W. F. Estética. São Paulo : Nova Cultural, 1997. p. 60.
} 
distintos para cada forma de arte - conforme afirmei anteriormente, a valorização do pintor e do literato enquanto artista se dá bem antes do músico. Para Elias, na primeira fase - a da arte artesanal - a criatividade do artista é totalmente subordinada ao consumidor de sua obra ${ }^{21}$. Esta fase corresponde, portanto, à música renascentista, ao barroco e à música clássica. $\mathrm{O}$ padrão artístico desses períodos é dado pelas cortes e com uma finalidade bem específica: o de distinguir-se socialmente ${ }^{22}$. Ou seja, a arte nesta fase tem um caráter funcional dado pelo grupo, e não pelo indivíduo em si mesmo ${ }^{23}$. Aliás, é sempre bom lembrar que as sociedades ocidentais do Antigo Regime, do qual a sociedade de corte, como formação social, faz parte, tinham de si próprias uma visão orgânica e hierarquizada ${ }^{24}$. O papel social do indivíduo era dado pelo grupo, numa perspectiva holista muito próxima daquilo que Elias descreve em seu clássico "Sociedade dos Indivíduos" 25 . O próprio músico não se destaca dos seus pares sociais através da sua produção; pelo contrário, sua arte apenas o define como um mero artesão. Para este tipo de sociedade, a arte acaba assumindo uma função de demarcação de um espaço coletivo, além de funcionar como elemento sociabilizante ${ }^{26}$.

O segundo período seria o da "arte de artista", que se inicia com o Romantismo. Nesse período, a criatividade do artista não segue necessariamente os ditames do gosto de seus consumidores. Ou seja, a arte e o artista ganham uma autonomia que lhes era negada até então ${ }^{27}$. Nesse momento, a arte perde inclusive seu caráter sociabilizante: seu público passa a ser formado por indivíduos fechados em si mesmos e dotados de uma autoconsciência bastante desenvolvida ${ }^{28}$. O artista, por sua vez, ganha um novo status à medida que se destaca socialmente com sua produção, surgindo daí o conceito de "gênio". O que ocorreu com Mozart, segundo Elias, é que ele quis ser artista quando não podia deixar de ser artesão.

Essas duas fases, que se sucederam no tempo, correspondem ao processo de maior diferenciação social que ocorre no Ocidente a partir do século X ou XI. Para Elias, até o século XIX há artesãos e, a partir daí, artistas. Este processo de diferenciação social, nesse sentido, operou tanto para dentro do meio musical quanto para fora.

\footnotetext{
${ }^{21}$ Id., p. 47.

${ }^{22}$ ELIAS, O processo..., p. 212.

${ }^{23}$ Id., p. 49.

${ }^{24}$ HESPANHA, A. M. e XAVIER, A. B. Representações da sociedade e do poder. In : MATTOSO,

J. (org.) História de Portugal. Lisboa : Estampa, 1994. v. 4 : O Antigo Regime. p. 122-125.

${ }^{25}$ ELIAS, N. Sociedade dos Indivíduos. Rio de Janeiro : Jorge Zahar Editor, 1994. p. 13-23.

${ }^{26}$ ELIAS, N. Mozart..., p. 49.

${ }^{27}$ Id., p. 47.

${ }^{28}$ Id., p. 51. 
Uma das mudanças que se observa entre a Renascença e o Barroco, em música, é a separação entre intérprete e compositor. Na Renascença, ela inexistia, e não foi sem resistência que foi surgindo, mais $\operatorname{tarde}^{29}$. O que se percebe é que as funções vão se diferenciando até um ponto, já no Romantismo, em que se pode falar em "mundo artístico", ou seja, um conjunto de pessoas e organizações que produzem $\operatorname{arte}^{30}$. Ou seja, para Elias, se por um lado, o processo de diferenciação social e complexificação das redes de interdependência atua no sentido de individualizar o artista, por outro, força uma complexificação do próprio fazer artístico. Nesse sentido, este autor submete a arte a toda uma série de transformações sociais que operam no sentido de individualizar artistas e consumidores, além de alterar suas relações. Estas transformações, para Elias, são extremamente lentas e não ocorrem sem percalços e resistências, "contramovimentos", como ele define. Muitas vezes tais transformações, que operam sobre o artista e sua obra, podem assumir feições dramáticas como no caso de Mozart, ou ainda, casos em que a moderna individualização do artista o leva a encarar com dificuldade sua posição social. Um exemplo disso é ilustrado pelo caso de Ana Cristina Cesar, poetisa brasileira que se suicidou em $1983^{31}$.

Mas, se para Elias a arte enquanto produto social acaba sofrendo os efeitos do processo civilizador, qual seria a sua função, de uma maneira geral?

Ele coloca o processo civilizador como um movimento na direção de uma regulação diferenciada dos impulsos, ou ainda, uma auto-regulação dos desejos, que passam a ser interiorizados. Ou seja, muda-se o equilíbrio da economia dos afetos, pois esta auto-regulação exige uma energia adicional no sentido de controlar pulsões e desejos. De certa forma, ocorre uma repressão do id, ou seja, um diminuição dos espaços de atuação do princípio do prazer. À arte, portanto, cabe o papel de contraponto a este processo, ou seja, ela tende a substituir o prazer reprimido pelo processo civilizador ${ }^{32}$. Ou seja, ela tende a ser uma espécie de "válvula de escape" para a pressão exercida pelo social, ainda que um escape totalmente controlado por este próprio social. A criação artística, para Elias, civiliza a manifestação dos desejos e das pulsões, na medida que se utiliza de formas dadas socialmente para a "sublimação do fluxo elementar de fantasia", como afirma o sociólogo ${ }^{33}$.

Quanto mais a diferenciação social opera, maior a rede de integração que nos abraça, e, por conseguinte, maior a energia necessária para o auto-

\footnotetext{
${ }^{29}$ HARNONCOURT, O diálogo..., p. 11-23.

${ }^{30}$ BECKER, H. Mundos artísticos e tipos sociais. In : VELHO, G. (org.). Arte e Sociedade : ensaios de sociologia da arte. Rio de Janeiro : Zahar Editores, 1977. p. 9-26.

${ }^{31}$ CASTELLO, J. Inventário das sombras. São Paulo : Record, 1999. p. 189-205.

${ }^{32}$ ELIAS, O processo..., p. 202-205.

${ }^{33}$ ELIAS, Mozart..., p. 61.
} 
controle de nossas pulsões ${ }^{34}$. A arte, para acompanhar este processo, individualizou tanto o criador quanto o consumidor e, segundo Elias, quanto maior a diferenciação social, maior o grau de individualização do artista e do público $^{35}$. O interessante é que, à medida que as formações sociais vão exigindo um maior autocontrole por parte dos indivíduos, mais o artista vai se diferenciando enquanto elemento da sociedade. A Idade Média, com um grau de interdependência social menor do que períodos posteriores, não nos legou "artistas", indivíduos que se destacassem por sua arte. Exceto por algumas exceções, como Giotto, a arte medieval é anônima. Na música, o maior nome do período é Guido D'Arezzo, mas não por sua música e sim pelas suas idéias no campo da notação musical. Por outro lado, o século XIX, que assiste ao limiar de uma civilização burguesa, industrial, e no qual os laços de interdependência são extremamente complexos em relação ao período medieval, tem no artista algo como um elemento fora da sociedade, extravagante, estranho. Na música os exemplos são muitos. Experimente o leitor comparar um retrato de Bach, com seu ar de "pai-de-família" responsável e cidadão temente a Deus, a um retrato de Beethoven. Não é sem sentido que este último sempre aparece com cabelos esvoaçantes, olhar sombrio, quase enlouquecido, como se sua vida fosse diferente da dos demais. Sua própria surdez é, nesse sentido, transformada em algo épico, como uma tragédia grega, um destino ao qual a alma sensível do artista não pode escapar. $\mathrm{O}$ artista do século XIX é a própria encarnação do lado selvagem do ser humano, e a imagem de Beethoven talvez seja o melhor exemplo disto ${ }^{36}$. Segundo o raciocínio de Elias, depositamos na arte aquilo que o processo civilizador nos leva a reprimir: nossos desejos e pulsões.

A análise do desenvolvimento da música no Ocidente pode, portanto, seguir esta idéia: formas musicais, estilos, se sucedem à medida que as próprias redes de interdependência que enlaçam o indivíduo vão se complexificando; resultado de um processo de repressão de desejos e sentimentos, ou seja, do processo civilizador, tal como descrito por Norbert Elias. Embora ele se utilize de alguns conceitos da psicologia, como o de sublimação - quando procura explicar o ponto de partida do impulso criativo dos indivíduos - a abordagem de Elias pode nos ajudar a analisar a música em relação à sua dependência das estruturas sociais. A atuação dos "gênios" - termo que o autor critica, sem que

\footnotetext{
${ }^{34}$ ELIAS, O processo..., p. 207-210.

${ }^{35}$ ELIAS, Mozart..., p. 47.

${ }^{36}$ Paganini, músico extremamente popular na Europa do século XIX, foi outro artista que este "caráter sombrio" acompanhou. Contava-se diversas histórias sinistras a seu respeito. Uma delas era relativa a um dos seus números preferidos. Durante as suas apresentações Paganini, um dos maiores virtuosos da história do violino, tinha o hábito de afrouxar três cordas de seu instrumento e solar somente com a corda que sobrara. Dizia-se, à época, que esta corda era feita com as tripas de uma amante que ele havia assassinado.
} 
lhe negue a existência - seria mediada por suas condições sociais. A "genialidade" de Mozart só se manifestou a partir da elaboração sobre material socialmente dado, além do fato de que ele próprio estava submetido a coerções de toda sorte. Daí a possibilidade da sociologia de um gênio.

\section{Bibliografia}

ANDRADE, Mário de. Introdução à Estética Musical. São Paulo: Hucitic, 1985.

Itatiaia, 1987. Pequena História da Música. Belo Horizonte:

CARPEAUX, Otto Maria. Uma Nova História da Música. Rio de Janeiro: Zahar Editores, 1958.

CASTELLO, José. Inventário das Sombras. São Paulo: Record, 1999.

COSTA, Clarice L. da. Uma Breve História da Música. São Paulo: Ars Poetica, 1992.

ELIAS, Norbert. Processo Civilizador. Rio de Janeiro: Jorge Zahar Editor, 1993. V. 2: formação do Estado e civilização.

Jorge Zahar Editor, 1995.

Mozart: Sociologia de um Gênio. Rio de Janeiro:

Sociedade dos Indivíduos. Rio de Janeiro: Jorge Zahar Editor, 1994.

HARNONCOURT, Nikolaus. O Diálogo Musical: Monteverdi, Bach e Mozart. Rio de Janeiro: Jorge Zahar Editor, 1993.

O Discurso dos Sons : caminhos para uma nova compreensão musical. Rio de Janeiro: Jorge Zahar Editor, 1990.

HEGEL. São Paulo: Nova Cultural, 1999. Série Os Pensadores.

LÉVI-STRAUSS, Claude. Olhar, Escutar e Ler. São Paulo: Companhia das Letras, 1997.

ROUSSEAU. São Paulo: Nova Cultural, 1999. Série Os Pensadores

TRAVASSOS, Elisabeth. Os Mandarins Milagrosos: arte e etnografia em Mário de Andrade e Béla Bartók. Rio de Janeiro: FUNARTE, 1997.

VELHO, Gilberto. Arte e Sociedade: ensaios de sociologia da Arte. Rio de Janeiro: Zahar Editores, 1977. 